\title{
Applying Low-Cost Air-Pollution Sensors' Information to Explore PM2.5 Concentration With an Emphasis on Spatial and Temporal Analysis: A Case in Chiayi City
}

\section{Chao-Heng Tseng}

National Taipei Institute of Technology: National Taipei University of Technology

Ling Ling Chen ( $\square$ amy@mail.ntut.edu.tw)

National Taipei Institute of Technology: National Taipei University of Technology

https://orcid.org/0000-0003-3776-9027

\section{Guan-Hua Tseng}

National Taipei University of Technology

\section{Research}

Keywords: Low-Cost Air-Pollution Sensors, Geographic Information System (GIS), Spatial and Temporal Analysis, Moran's I, Local Indicators of Spatial Association (LISA), Particulate Matter (PM2.5)

Posted Date: August 18th, 2021

DOl: https://doi.org/10.21203/rs.3.rs-796520/v1

License: (c) (1) This work is licensed under a Creative Commons Attribution 4.0 International License.

Read Full License 


\section{Abstract}

Low-cost air-pollution sensors are attracting increasing attention. They offer air-pollution monitoring at a cost lower than that of conventional methods, theoretically facilitating air-pollution monitoring in several locations and immediate application of acquired information. We establish a particulate matter $\left(\mathrm{PM}_{2.5}\right)$ map based on low-cost air-pollution sensor information developed using internet of things at Taiwan's Environmental Protection Agency. We synergize data from one monitoring station with 287 low-cost airpollution-pollution sensors (data entries $=\sim 50$ million) to estimate $\mathrm{PM}_{2.5}$ concentrations from September 1, 2018 to August 31, 2019. We investigate Chiayi City because it has the second-highest $\mathrm{PM}_{2.5}$ concentration in Taiwan. By analyzing Geographic Information System data, we map Chiayi City's spatial and temporal distributions, identify $\mathrm{PM}_{2.5}$, and recognize the characteristics of Chiayi City's hotspots. Our main discoveries are as follows: Chiayi City's spatial distribution reveals $\mathrm{PM}_{2.5}$ concentrated in its industrial area, which increasingly reduces from the industrial area to the city center. Hot spots are identified by two types of space units: northwest industrial and central and western agricultural zone. Concentrated $\mathrm{PM}_{2.5}$ occurs mainly in winter, with the highest rate in January, occurring most frequently and less frequently from 7 to 10 a.m. and 3 to 5 p.m., respectively. Although this study focuses on Chiayi City, the proposed approach has general applicability to wide-ranging environment-monitoring studies and air-pollution interventions and will substantially assist in validating $\mathrm{PM}_{2.5}$ transport models and enhance exposure estimation accuracy in further research.

\section{Introduction}

The technology of low-cost air-pollution sensors has been advancing and widely applied in spatial analysis [1-3]. The price advantage of sensors promotes the acquisition of air pollution information, especially in the collection of spatial and temporal distribution data [4] and has improved cognition of air quality and health situation [5].

Because of the technological progress in low-cost air-pollution sensors, large-scale distributed air sensor networks in the city to collect environmental data have been implemented for smart city initiatives [6]. Additionally, understanding the limitations and capabilities is important [7]. Taiwan's Environmental Protection Agency (EPA) established an air network (https://wot.epa.gov.tw/) to obtain fine-scale airpollution information. Some studies have also used large-scale distributed air sensor networks to finish their studies $[6,8,9]$.

Air pollution affects countries around the world and can even cause serious human health issues, such as cardiovascular disease, respiratory disease, and premature death $[6,10,11]$. Among air pollutants, fine particulate matter $\left(\mathrm{PM}_{2.5}\right)$ is the main problem in many countries. Owing to the different distribution of emission sources and meteorological conditions, $\mathrm{PM}_{2.5}$ has a significant temporal and spatial variation in space $[6,12,13]$. Therefore, it is necessary for urban environmental planning and air quality planning 
and managers to determine the hot spots and sources of air pollution, and to understand the temporal and spatial patterns of regional $\mathrm{PM}_{2.5}[6,14,15]$.

Some studies use low-cost sensors to detect the $\mathrm{PM}_{2.5}$ status in the area, but they did not use more detailed spatial and temporal analysis of the distribution $[6,16,17]$. The city's day and night cycles are different, and exposure to air pollutants will also be affected [6]. However, there are few studies that can predict $\mathrm{PM}_{2.5}$ from hourly to daily, which is of great importance for human health related research on short-term and long-term exposure to $\mathrm{PM}_{2.5}[3,18-20]$.

Furthermore, few studies have used low-cost sensor measurements of air pollution to improve $\mathrm{PM}_{2.5}$ prediction at the hourly level. We demonstrated this approach by synergizing the data from 1 monitoring station with 287 low-cost air-pollution sensors (the amount of data entries is $\sim 50$ million) to estimate concentrations of $\mathrm{PM}_{2.5}$ at a resolution of $200 \mathrm{~m}$ by using low-cost air-pollution sensor data $\left(1 \mathrm{PM}_{2.5}\right.$ data in 3 minutes) from Taiwan's EPA air network from September 1, 2018, to August 31, 2019.

In this study, we investigated the situation in Chiayi City as a case study because it has the secondhighest $\mathrm{PM}_{2.5}$ concentration in all the cities in Taiwan. The main goals of this case study are to promote the understanding of the utility of emerging air sensor technology when deployed in a sensor air network and then to evaluate whether sensor technology provides useful supplemental information to existing regulatory ambient air monitoring systems. Additionally, the ordinary Kriging interpolation, Moran's I, and local indicators of spatial association (LISA) were combined to analyze the spatial distribution of $\mathrm{PM}_{2.5}$ and identify pollution hotspots. We expect this study to demonstrate the considerable applicability of lowcost air-pollution sensors for the monitoring of air quality as well as combining the application of GIS and statistics, after referring to the real-time data, the base map can be modified and the space and time division map can be displayed instantly.

\section{Materials And Methods}

In this section, we briefly describe the low-cost air-pollution sensors developed by the internet of things (IoT) of the EPA in Taiwan, namely the spatial and temporal analysis of the $\mathrm{PM}_{2.5}$ map of the site constructed using GIS data analysis in this study.

\subsection{Low-cost air-pollution sensors developed by Taiwan's EPA}

Taiwan's EPA has been promoting the smart concept plan "Environmental quality sensing loT development and implementation and law enforcement applications." This plan was developed by the loT and deploys micro-sensors to monitor air quality at the street scale (space) and minute scale (time), strengthens the spatial and temporal monitoring of air quality, and assists and strengthens the spatial and temporal distribution of the EPA's national air product network of measurement stations [21]. In addition, the specific sensing principles are based on the application of polluted hot areas, environmental 
education, or supplementary sensing in areas, without the measurement stations recommended by the United States EPA Air Sensor Guidebook, and are divided into industrial sensing points (monitoring factory-dense areas) and community sensing points (one category: large communities near large pollution sources), traffic sensing points (monitoring busy areas), and auxiliary sensing points (towns and towns without standard monitoring stations within $20 \mathrm{~km}$ ) [22].

Thus far, 8,300 air-pollution sensors have been deployed; covering 226 district-level administrative districts, 105 industrial parks and science parks, and they monitor more than 60,000 pipeline plants [23]. The low-cost air-pollution sensors provide the temperature, relative humidity, $\mathrm{PM}_{2.5}$, and other sensing data every 3 minutes. Taiwan's EPA air network can assess the aforementioned air-pollution sensor points every 3 minutes by using sensing data (https://wot.epa.gov.tw/).

\subsection{Design in the study}

This section presents the materials used and the methodology adopted in this study. We describe the study area, the pollution maps used, and the spatial and temporal analysis.

\subsubsection{Study area description}

Chiayi City is the third largest city in Taiwan. This city has an area of approximately $60 \mathrm{~km}^{2}$, a population of 27 million, a population density of 4.5 thousand, and a subtropical climate with temperatures ranging between $22^{\circ} \mathrm{C}$ and $33^{\circ} \mathrm{C}$. During the study period, we observed that north was the predominant wind direction, with wind speeds typically greater than $2.3 \mathrm{~m} / \mathrm{s}$ during the daytime. Chiayi City has dense and scattered industrial areas and the second-highest $\mathrm{PM}_{2.5}$ concentration in Taiwan. Figure 1 presents the description of the study area considered for pedestrian exposure monitoring (1 monitoring station with 287 low-cost air-pollution sensors).

\subsubsection{Pollution mapping}

We obtained the $\mathrm{PM}_{2.5}$ map after a spatial interpolation of the concentration of low-cost air-pollution sensors. The spatial interpolation used a geostatistical method: "Kriging" that considered space configuration around the measuring point [24]. Related Kriging and low-cost air-pollution sensors have been applied in air-pollution yield [13, 25-27].

Geographic information systems (GISs) have been applied in the field of air quality research and produced fruitful results $[28,29]$. The grid processing was $200 \mathrm{~m}^{2}$ of fishnet and had 1635 grids (Fig. 2).

In this study, we used ArcMap 10.5 in ArcGIS, developed by Environmental Systems Research Institute, to interpolate the $\mathrm{PM}_{2.5}$ concentration of 287 low-cost air-pollution sensors near the study area of Chiayi City. The estimated time categories were annual average concentration, seasonal average concentration, monthly average concentration, and hour average concentration, and we expected to produce a more detailed analysis of the time and space characteristics of Chiayi City on different time scales than is 
available in the literature. After producing the pollution map, we identified the concentration hotspots of $\mathrm{PM}_{2.5}$ at each time scale.

\subsubsection{Spatial and temporal analysis}

Spatial interpolation can be used to obtain a $\mathrm{PM}_{2.5}$ map, but there was a lack of spatial statistical significance, and obtaining an immediate understanding of the spatial variability of $\mathrm{PM}_{2.5}$ concentration information was the focus of this research. Moran's I and LISA were used in this study. Using Moran's I, we realized the relationship between the size and location of each spatial unit in the study area; using LISA, we explored hot points, assisted the influence from hot points, and identified "outliers" [30].

Moran's I measures spatial autocorrelation in statistics, and the formula is as follows:

$$
I=\frac{n \Sigma_{i} \Sigma_{j W_{i j\left(x_{i}-\bar{x}\right)\left(x_{j}-\bar{x}\right)}}}{\Sigma_{i} \Sigma_{j} W_{i j} \Sigma_{i}\left(x_{i}-\bar{x}\right)^{2}}
$$

where $n$ is the number of spatial units indexed by $i$ and $j, x$ is the variable of interest, $\bar{x}$ is the mean of $x$, $W_{i j}$ is a matrix of spatial weights with zeroes on the diagonal (i.e., $W_{i i}=0$ ), and $W$ is the sum of all $W_{i j}$.

When the $\mathrm{Z}$ score or $\mathrm{p}$ value indicates significance, a positive Moran's I index number indicates a tendency toward clustering, and a negative Moran's I index number indicates a toward dispersion At a significance level of $95 \%$, a Z score greater than 1.96 represents a significant clustering distribution in the region. When the $Z$ score is between 1.96 and -1.96 , it represents a random distribution in space, and when the $Z$ score less than -1.96 , it represents a spatial distribution. The distribution within the unit is negatively correlated. Additionally, LISA is a statistic that evaluates the existence of clusters in the spatial arrangement of a given variable. LISA and Moran's I have the same concept of confidence level significance, and LISA can present five states of spatial clustering.

However, the most recent research on spatial autocorrelation (Moran's I or LISA) of air-pollution concentration distribution has been dominated by studies of East Asia [31-33], and this topic is a focus of this study.

\section{Results And Discussion}

Figure 3 shows $\mathrm{PM}_{2.5}$ pollution concentration in Chiayi City. The annual average $\mathrm{PM}_{2.5}$ concentration range is from $21.89 \mu \mathrm{g} / \mathrm{m}^{3}$ to $27.14 \mu \mathrm{g} / \mathrm{m}^{3}$, equivalent to a spatial concentration difference of 5.25 $\mu \mathrm{g} / \mathrm{m}^{3}$. The highest concentration occurs in the industrial zone in the northwest, and the lowest concentration occurs in the south. Figure 4 shows the Moran's I distribution: Moran's I is $0.9784>0$ and close to 1 , indicating that the annual average $\mathrm{PM}_{2.5}$ concentration in Chiayi City has strong spatial clustering, and the $Z$ score is $53.80>2.58$, indicating that under the $99 \%$ confidence level, it has 
significant cluster distribution. Figure 5 shows LISA in Chiayi City, and hot spots are identified by two types of space units: the northwest industrial zone and the central and western agricultural zone.

Table 1 shows the Moran's I result in the four seasons: The concentration distribution in the four seasons had significant clustering characteristics, and there were more obvious distribution differences in the spring and summer than in the autumn and winter. Figure 6 shows the $\mathrm{PM}_{2.5}$ concentration LISA in the four seasons in Chiayi City. The distribution of hot areas was only significantly different from other seasons in the summer, and high pollution values were clustered further north, which is speculated to be somewhat related to the prevailing wind direction of the seasons; cold areas differed in eastern Chiayi City between the summer and autumn and the spring and winter.

Table 1

Moran's I result in the four seasons

\begin{tabular}{|lll|}
\hline Season & Moran's I & Z score \\
\hline Spring & 0.9710 & 53.40 \\
\hline Summer & 0.9855 & 54.19 \\
\hline Autumn & 0.9785 & 53.79 \\
Winter & 0.9814 & 53.98 \\
\hline
\end{tabular}

Table 2 shows the Moran's I result by month. All months show significant clustering at the $99 \%$ confidence level. However, the cluster intensity increased from January to June, and the maximum value of Moran's I was 0.9893 . It slowly decreased to 0.9579 before October, and in November after December, the spatial distribution is more discrete than in June. 
Table 2

Moran's I result by month

\begin{tabular}{|lll|}
\hline Month & Moran's I & Z score \\
\hline January & 0.9651 & 53.07 \\
\hline February & 0.9761 & 53.68 \\
\hline March & 0.9801 & 53.90 \\
\hline April & 0.9806 & 53.96 \\
\hline May & 0.9819 & 54.00 \\
\hline June & 0.9893 & 54.40 \\
\hline July & 0.9819 & 54.00 \\
\hline August & 0.9737 & 53.55 \\
\hline September & 0.9737 & 53.55 \\
\hline October & 0.9579 & 52.67 \\
\hline November & 0.9781 & 53.78 \\
\hline December & 0.9700 & 53.34 \\
\hline
\end{tabular}

From January to April, the distribution of the hot zone did not change much, and the relative change in the cold zone increased. By April, the range of the cold zone in the east was significantly reduced, and its land use included the government land, water area, and agricultural land. Starting in June, the hot area moved north. In July, the hot area was separated from the downtown area, such as Chiayi Railway Station. In October, the hot area resumed the spring and annual average hot area distribution pattern.

The inference of this study's results is that wind direction caused the pollution source in the central and western hot area of Chiayi City to move north due to the southwest wind.

According to the Meteorological Bureau's explanation of Taiwan's monsoons, "Taiwan's weather gradually warms in April each year, and the summer monsoon can blow in slowly. After June, the land temperature is high, and the low air pressure on the mainland has developed to a considerable extent. The summer monsoon blows into Taiwan from the ocean until August, the peak period."

After September, the sun hits the southern hemisphere directly, and the cold air masses in the northern hemisphere strengthen. The parts of Siberia and Mongolia at high latitudes are colder than the ocean is. The cold air sinks, increasing the air pressure on the ground and forming high air pressure, and the Pacific Ocean has relatively low air pressure. The wind blows from inland China to the Pacific Ocean to Taiwan to form the northeast monsoon. After October, the wind direction gradually stabilizes, and it becomes unstable from December to February. After March, the monsoon gradually decays and repeats the cycle. Figures 7 to 8 show the monthly $\mathrm{PM}_{2.5}$ concentration LISA in Chiayi City. 
A novel contribution of this study is that $\mathrm{PM}_{2.5}$ concentration was developed at the hourly level. Notably, most of the $\mathrm{PM}_{2.5}$ models in the literature have been annual, seasonal, monthly, or daily [16, 33-35].

Table 3 shows the Moran's I result at hours. All the hour intervals showed significant clustering under the $99 \%$ confidence level. However, the clustering intensity of Moran's I value ranged from 0.9597 to 0.9898 , and the $Z$ score value ranged from 52.77 to 54.41 was much greater than 2.58 . The most intense clustering phenomenon occurred between 1 and 2 a.m., and the most relative dispersion occurred between 11 and 12 a.m. This result shows the obvious zoning phenomena in the $\mathrm{PM}_{2.5}$ concentration in Chiayi at any time, and understanding the location of hot and cold areas in the space is necessary. The LISA analysis method must also be used. 
Table 3

Moran's I result (hourly)

\begin{tabular}{|lll|}
\hline Hours & Moran's I & Z score \\
\hline 0-1 o'clock & 0.9853 & 54.17 \\
\hline 1-2 o'clock & 0.9860 & 54.21 \\
\hline 2-3 o'clock & 0.9871 & 54.27 \\
\hline 3-4 o'clock & 0.9895 & 54.40 \\
\hline 4-5 o'clock & 0.9898 & 54.41 \\
\hline 5-6 o'clock & 0.9893 & 54.39 \\
\hline 6-7 o'clock & 0.9893 & 54.38 \\
\hline 7-8 o'clock & 0.9891 & 54.38 \\
\hline 8-9 o'clock & 0.9842 & 54.11 \\
\hline 9-10 o'clock & 0.9753 & 53.62 \\
\hline $10-11$ o'clock & 0.9668 & 53.15 \\
\hline $11-12$ o'clock & 0.9628 & 52.93 \\
\hline $12-13$ o'clock & 0.9597 & 52.77 \\
\hline $13-14$ o'clock & 0.9613 & 52.86 \\
\hline $14-15$ o'clock & 0.9627 & 52.94 \\
\hline $15-16$ o'clock & 0.9617 & 52.88 \\
\hline $16-17$ o'clock & 0.9654 & 53.09 \\
\hline $17-18$ o'clock & 0.9725 & 53.49 \\
\hline $18-19$ o'clock & 0.9776 & 53.76 \\
\hline $19-20$ o'clock & 0.9817 & 53.98 \\
\hline 20-21 o'clock & 0.9829 & 54.04 \\
\hline 21-22 o'clock & 0.9832 & 54.06 \\
\hline 22-23 o'clock & 0.9840 & 54.10 \\
\hline 23-24 o'clock & 0.9849 & 54.15 \\
\hline
\end{tabular}

In addition to being affected by instability, the hourly average concentration in Chiayi City may also increase the mixed layer due to solar radiation. The high wind speeds starting at 8 a.m. also spreads pollutants. Figures 9 to 12 show the $\mathrm{PM}_{2.5}$ concentration LISA per hour in Chiayi City. 
We performed LISA regional spatial autocorrelation analysis, under a $95 \%$ confidence level, and found different clustering characteristics in different hour intervals, especially during the day. For the $\mathrm{PM}_{2.5}$ high concentration hot zone, the difference between day and night was obvious, especially in the east of the city center, including commercial areas, residential areas, and school land, which appear relativity during the day from 9 to $10 \mathrm{a} . \mathrm{m}$. The phenomenon of concentration clustering gradually moved to the south from 10 a.m. to 2 p.m., reached the north from 1 to 2 p.m., and gradually shrunk from 2 to 9 p.m. No significant clustering in space was observed after 9 p.m. The largest area of $\mathrm{PM}_{2.5}$ gathering hot zone in the space was in the downwind of the industrial zone; the cluster area extended to the southeast commercial area starting at 4 a.m., and the concentration of the downwind of the industrial zone gradually disappeared until 4 p.m.

The difference in distribution of $\mathrm{PM}_{2.5}$ between day and night was also observed in the cold areas where the concentration was low. $\mathrm{PM}_{2.5}$ in the cold areas in the eastern part of Chiayi City gradually disappeared after 10 a.m. while local parts were observed between 2 and 4 p.m. The occurrence of hot zones was observed, and this area was dominated by forest areas and protected areas.

A particulate matter $\left(\mathrm{PM}_{2.5}\right)$ map was built in this study by using low-cost air-pollution sensor information developed by the IoT of the EPA in Taiwan. We demonstrated this approach by synergizing the data from 1 monitoring station with 287 low-cost air-pollution sensors (the amount of data entries is $\sim 50$ million) to estimate $\mathrm{PM}_{2.5}$ concentrations from September 1, 2018, to August 31, 2019. The $\mathrm{PM}_{2.5}$ real-time observation network is of great importance under the control of air quality. Real-time data through the reduces air pollution, and it also benefits the health of residents living in Chiayi City. [36] presented results similar to those of this study. Additionally, Yougeng et al. [3] indicated that the increasing use of low-cost air quality sensor networks increased their ability to capture $\mathrm{PM}_{2.5}$ gradients at the neighborhood scale and collect more spatially and temporally resolved $\mathrm{PM}_{2.5}$ data for epidemiological and environmental justice studies.

The results of hourly $\mathrm{PM}_{2.5}$ space and time analysis can be used to understand the distribution of $\mathrm{PM}_{2.5}$ in real time through the graph. It can also be helpful for epidemiological research, such as cardiovascular or respiratory disease, especially in the analysis and discussion of immediate health shocks and diseases that may be caused by human exposure to $\mathrm{PM}_{2.5}$. Additionally, hourly real-time spatial distribution can be applied to real-time prediction of air quality in events such as air pollution and natural disasters. Nowadays, whether cities or regions are facing environmental issues such as climate change, greenhouse gases, air pollution, and natural disasters, if there are real-time spatial distribution maps to understand the current situation, damage to human activities or commercial behavior can be reduced.

Because the emission path of air pollution is composed of many complicated methods, in the past, the atmospheric diffusion model was used to predict the distribution of $\mathrm{PM}_{2.5}$. Owing to the calculation of physical chemistry, the parameters are complicated, and it is not easy to plot the map immediately. Even if the results are predicted by statistics or machine learning, it is difficult for the terrain and 
meteorological influences to be accurately considered; thus, the aforementioned two are combined as follows: the front-end uses atmospheric diffusion mode to accurately calculate the terrain and meteorological influences to make a base map, and the back end uses GIS and statistical reference realtime data to modify the base map and display the plot instantaneously. Some studies [19-21, 37] have presented the spatiotemporal $\mathrm{PM}_{2.5}$ "machine learning" model, and it improved the relationship between spatial and temporal predictions in the city. In further research, "machine learning" methods can also be expanded to predict the characteristics of $\mathrm{PM}_{2.5}$ concentration and include other features, for example, meteorological conditions in the city. This study also provides a reference for urban development and urban-rural planners.

\section{Conclusion}

In this study, to estimate hourly intra-urban $\mathrm{PM}_{2.5}$ distribution patterns in Chiayi City, we established a $\mathrm{PM}_{2.5}$ concentration map by integrating spatial and temporal analysis from a low-cost air sensor network developed by Taiwan's EPA, highly resolved data, and a suite of spatiotemporal variables. In addition, in contrast with the literature $[16,21,33-35]$, we developed $\mathrm{PM}_{2.5}$ concentration at the hourly level and demonstrated the prospective applicability of Moran's I analysis and LISA in evaluating the immediate spatial and temporal distribution of $\mathrm{PM}_{2.5}$ can be used to explore the pattern of air pollution in cities and regions.

Although this research has contributed to real-time air quality control, it has its limitations. First, $\mathrm{PM}_{2.5}$ will be affected by various pollutants, including, $\mathrm{SO}_{2}, \mathrm{NOx}$, and $\mathrm{O}_{3}$. Therefore, this study suggests that in further research in the future, the air pollution situation before $\mathrm{PM}_{2.5}$ should be formed based on the realtime spatial distribution results of current development. The precise causes and factors should be understood so that cities and regions can be provided with better research results when planning and managing air quality. In addition, the application of low-cost air sensors is becoming more and more popular, which can gradually improve and strengthen the capabilities of science, technology, and research. In the future, the scope of using low-cost air sensors will continue to increase to improve the accuracy of real-time space and time distribution. In addition, more detailed technologies (for example: real-time space and time distribution every minute or every second) to serve as a reference for urban planning and air quality planning in cities and regions should be developed.

Ultimately, this study provides valuable $\mathrm{PM}_{2.5}$ real-time hotspot distribution in space and time, which can be applied to issues related to immediate health shocks and health losses in the future as well as the impact on urban and urban planning based on air pollution and health considerations.

\section{Declarations}

Declarations: All authors have declared that: (i) no support, financial or otherwise, has been received from any organization that may have an interest in the submitted work; and (ii) there are no other relationships 
or activities that could appear to have influenced the submitted work.

Availability of data and material: The data that support the findings of this study are available in Air Network at https://wot.epa.gov.tw/. These data were derived from the following resources in the public domain: Forward-looking infrastructure design painting (https://pm25.lass-net.org/) and Real-time air quality map (https://www.airq.org.tw/).

Competing interests: The author has declared that there are no competing interests.

Funding: This research did not receive any specific grant from funding agencies in the public, commercial, or not-for-profit sectors.

Author's contributions: Chao-Heng, Tseng: Conceptualization, Methodology, Project administration; LingLing, Chen: Writing - Original Draft, Writing - Review \& Editing; Guan-Hua, Tseng: Data Curation, Software, Validation, Visualization

Acknowledgments: The authors are grateful to Taiwan EPA for the air network data set and thank reviewers for their valuable suggestions.

\section{References}

1. Shi X, Zhao C, Jiang JH, Wang C, Yang X, Yung YL. Spatial representativeness of $P M_{2.5}$ concentrations obtained using observations from network stations. J Geophys Res Atmos. 2018;123(6):3145-58. doi: 10.1002/2017JD027913.

2. Zhao C, Wang Y, Shi X, Zhang D, Wang C, Jiang JH, et al. Estimating the contribution of local primary emissions to particulate pollution using high-density station observations. J Geophys Res Atmos. 2019;124(3):1648-61. doi: 10.1029/2018JD028888.

3. Yougeng L, Giulianoa G, Habre R. Estimating hourly PM2.5 concentrations at the neighborhood scale using a low-cost air sensor network: A Los Angeles case study. Environ Res.2021;195. PMID 110653.

4. Kaufman R. Practical strategic leadership: aligning human performance development with organizational contribution. Perf Improv. 2017;56(2):16-21. doi: 10.1002/pfi.21664.

5. Ramaswami A, Russell AG, Culligan PJ, Sharma KR, Kumar E. Meta-principles for developing smart, sustainable, and healthy cities. Science. 2016;352(6288):940-3. doi: 10.1126/science.aaf7160, PMID 27199418.

6. Cao R, Li B, Wang Z, Peng ZR, Tao S, Lou S. Using a distributed air sensor network to investigate the spatiotemporal patterns of $\mathrm{PM}_{2.5}$ concentrations. Environ. Pollut. 2020;264, PMID 114549

7. Rai AC, Kumar P, Pilla F, Skouloudis AN, Di Sabatino S, Ratti C, et al. End-user perspective of low-cost sensors for outdoor air pollution monitoring. Sci Total Environ. 2017;607:691-705. doi: 10.1016/j.scitotenv.2017.06.266, PMID 28709103. 
8. Moltchanov S, Levy I, Etzion Y, Lerner U, Broday DM, Fishbain B. On the feasibility of measuring urban air pollution by wireless distributed sensor networks. Sci Total Environ. 2015;502:537 - 47. doi: 10.1016/j.scitotenv.2014.09.059, PMID 25300018.

9. Kizel F, Etzion Y, Shafran-Nathan R, Levy I, Fishbain B, Bartonova A, et al. Node-to-node field calibration of wireless distributed air pollution sensor network. Environ Pollut. 2018;233:900-9. doi: 10.1016/j.envpol.2017.09.042, PMID 28951042.

10. GBD 2015 Risk Factors Collaborators. Global, regional, and national comparative risk assessment of 79 behavioural, environmental and occupational, and metabolic risks or clusters of risks, 19902015: a systematic analysis for the Global Burden of Disease Study 2015. Lancet. 2016;388(10053):1659-724. doi: 10.1016/S0140-6736(16)31679-8, PMID 27733284.

11. Lelieveld J, Haines A, Pozzer A. Age-dependent health risk from ambient air pollution: a modelling and data analysis of childhood mortality in middle-income and low-income countries. Lancet Planet Health. 2018;2(7):e292-300. doi: 10.1016/S2542-5196(18)30147-5, PMID 30074892.

12. Yuan $\mathrm{C}, \mathrm{Ng} \mathrm{E}$, Norford LK. Improving air quality in high-density cities by understanding the relationship between air pollutant dispersion and urban morphologies. Build Environ. 2014;71:245 58. doi: 10.1016/j.buildenv.2013.10.008, PMID 32288025.

13. Li C, Wang Z, Li B, Peng ZR, Fu Q. Investigating the relationship between air pollution variation and urban form. Build Environ. 2019;147:559-68. doi: 10.1016/j.buildenv.2018.06.038.

14. Lin C, Li Y, Yuan Z, Lau AKH, Li C, Fung JCH. Using satellite remote sensing data to estimate the highresolution distribution of ground-level $\mathrm{PM}_{2.5}$. Remote Sens Environ. 2015; 156:117-28. doi: 10.1016/j.rse.2014.09.015.

15. Yang D, Lu D, Xu J, Ye C, Zhao J, Tian G, et al. Predicting spatio-temporal concentrations of PM2.5 using land use and meteorological data in Yangtze River Delta, China. Stoch Environ Res Risk Assess. 2018;32(8):2445-56. doi: 10.1007/s00477-017-1497-6.

16. Bi J, Stowell J, Seto EYW, English PB, Al-Hamdan MZ, Kinney PL, et al. Contribution of low-cost sensor measurements to the prediction of $\mathrm{PM}_{2.5}$ levels: A case study in Imperial County, California, USA. Environ Res. 2020;180:108810. doi: 10.1016/j.envres.2019.108810.

17. Jiayu L, Zhanga $\mathrm{H}$, Chaoa C-Y, Chien CYW, Luo CH, Chen LJ, et al.. Integrating low-cost air quality sensor networks with fixed and satellite monitoring systems to study ground-level $\mathrm{PM}_{2.5}$. Atmos Environ. 2020;223. PMID 117293.

18. Di Q, Kloog I, Koutrakis P, Lyapustin A, Wang Y, Schwartz J. Assessing $\mathrm{PM}_{2.5}$ exposures with high spatiotemporal resolution across the continental United States. Environ Sci Technol. 2016;50(9):4712-21. doi: 10.1021/acs.est.5b06121, PMID 27023334.

19. Hu X, Belle JH, Meng X, Wildani A, Waller LA, Strickland MJ, et al. Estimating $\mathrm{PM}_{2.5}$ concentrations in the conterminous United States using the random forest approach. Environ Sci Technol. 2017;51(12):6936-44. doi: 10.1021/acs.est.7b01210, PMID 28534414. 
20. Brokamp C, Jandarov R, Hossain M, Ryan P. Predicting daily urban fine particulate matter concentrations using a random forest model. Environ Sci Technol. 2018;52(7):4173-9. doi: 10.1021/acs.est.7b05381, PMID 29537833.

21. Environmental Protection Administration executive Yuan. 9/15 https://airtw.epa.gov.tw/CHT/Encyclopedia/AirSensor/AirSensor.aspx. Accessed 15 September 2020.

22. Environmental Protection Administration executive Yuan (EPAb). 9/15 https://airtw.epa.gov.tw/CHT/Encyclopedia/AirSensor/AirSensor_3.aspx. Accessed 15 September 2020.

23. Environmental Protection Administration executive Yuan. 9/15 https://airtw.epa.gov.tw/CHT/Encyclopedia/AirSensor/AirSensor_4.aspx. Accessed 15 September 2020.

24. ESRI ArcGIS. 9/15, https://www.esri.com/en-us/arcgis/about-arcgis/overview. Accessed 01 April 2020.

25. Kumar P, Morawska L, Martani C, Biskos G, Neophytou M, Di Sabatino S, et al. The rise of low-cost sensing for managing air pollution in cities. Environ Int. 2015;75:199-205. doi: 10.1016/j.envint.2014.11.019, PMID 25483836.

26. Mead MI, Popoola OAM, Stewart GB, Landshoff P, Calleja M, Hayes M, et al. The use of electrochemical sensors for monitoring urban air quality in low-cost, high-density networks. Atmos Environ. 2013;70:186-203. doi: 10.1016/j.atmosenv.2012.11.060.

27. Karagulian F, Barbiere M, Kotsev A, Spinelle L, Gerboles M, Lagler F, et al. Review of the performance of low-cost sensors for air quality monitoring. Atmosphere. 2019;10(9):1-41. doi: 10.3390/atmos10090506.

28. Usmani RSA, Hashem IAT, Pillai TR, Saeed A, Abdullahi AM. Geographic information system and big spatial data: a review and challenges. Int J Enterpr Inf Syst. 2020;16(4):101-45. doi: 10.4018/IJEIS.2020100106.

29. Gryech I, Ghogho M, Elhammouti H, Sbihi N, Kobbane A. Machine learning for air quality prediction using meteorological and traffic related features. J Ambient Intell Smart Environ;12(5):379-91. doi: 10.3233/AIS-200572.

30. Luc A. Local indicators of spatial association-LISA. Geogr Anal. 1995;27(2):93-115.

31. Ping J, Gao Y, Liu L, Peng Zh, Wu H. Maternal health and green spaces in China: A longitudinal analysis of MMR based on spatial panel mode. Healthcare (Basel). 2019;7(4): 154.

32. Shen $Y$, Zhang L, Fang X, Ji H, Li X, Zhao Z. Spatiotemporal patterns of recent $\mathrm{PM}_{2.5}$ concentrations over typical urban agglomerations in China. Sci Total Environ. 2019;655:13-26. doi: 10.1016/j.scitotenv.2018.11.105, PMID 30469058.

33. Chen G, Li S, Knibbs LD, Hamm NAS, Cao W, Li T, et al.. A machine learning method to estimate $\mathrm{PM}_{2.5}$ concentrations across China with remote sensing, meteorological and land use information. Sci Total Environ. 2018;636:52-60. doi: 10.1016/j.scitotenv.2018.04.251, PMID 29702402. 
34. Cohen AJ, Brauer M, Burnett R, Anderson HR, Frostad J, Estep K et al. Estimates and 25- year trends of the global burden of disease attributable to ambient air pollution: an analysis of data from the Global Burden of Diseases Study 2015. Lancet. 2017;389(10082):1907-18. doi: 10.1016/S01406736(17)30505-6, PMID 28408086.

35. Huang K, Xiao Q, Meng X, Geng G, Wang Y, Lyapustin A, et al. Predicting monthly high-resolution PM2.5 concentrations with random forest model in the North China Plain. Environ Pollut. 2018;242(A):675 - 83. doi: 10.1016/j.envpol.2018.07.016, PMID 30025341.

36. Kelly FJ, Fusse JCII. Air pollution and public health: emerging hazards and improved understanding of risk. Environ Geochem Health. 2015;37(4):631-49. doi: 10.1007/s10653-015-9720-1

37. Xiyao C, Li F, Zhanga J, Zhou W, Wanga X, Fu H. Spatiotemporal mapping and multiple driving forces identifying of $\mathrm{PM}_{2.5}$ variation and its joint management strategies across China. J Clean Prod. 2018;250. PMID 119534.

\section{Figures}



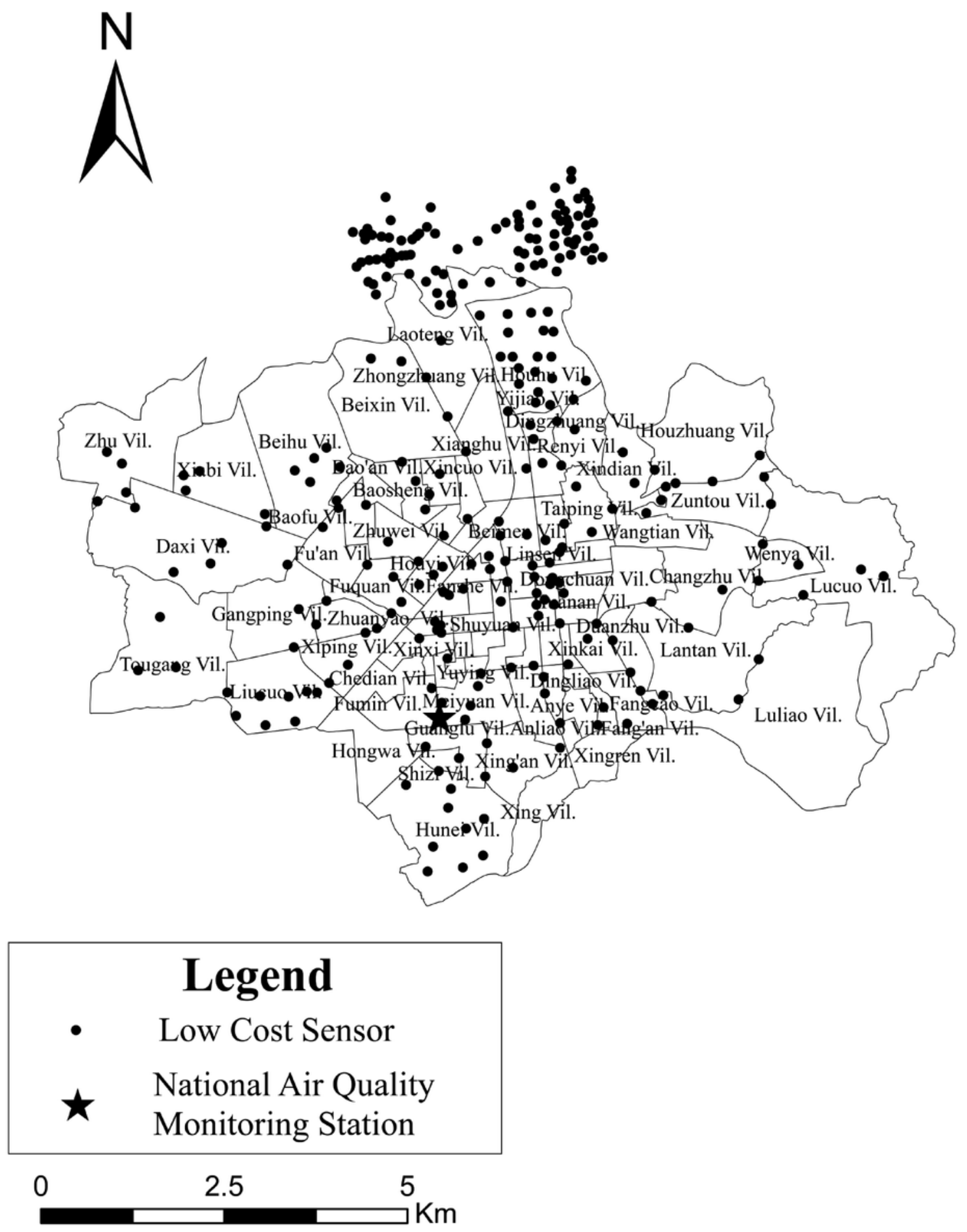

Figure 1

Study area (1 monitoring station with 287 low-cost air-pollution sensors) 


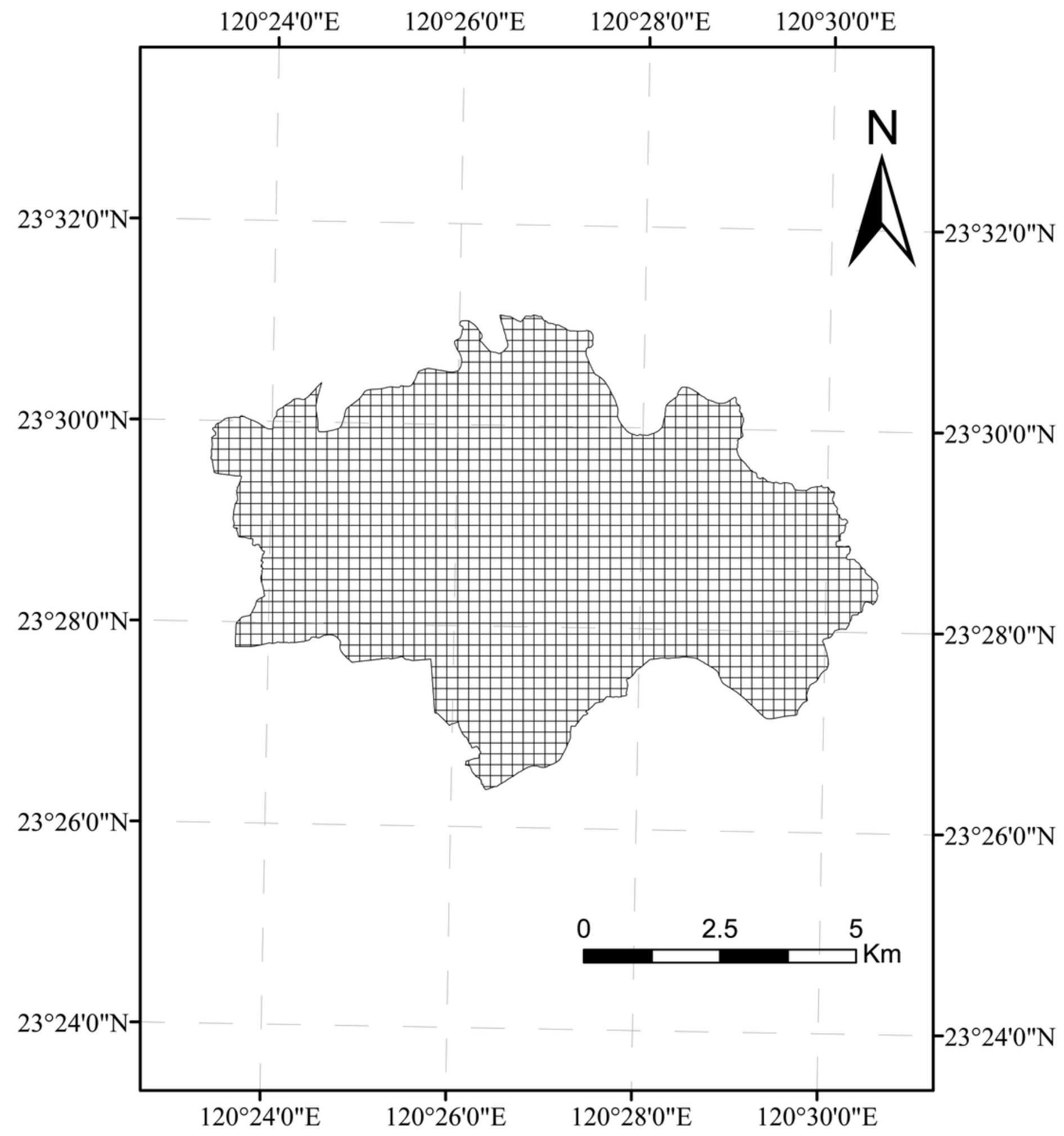

Figure 2

Grid processing (200 m2 fishnet, 1635 grids) 


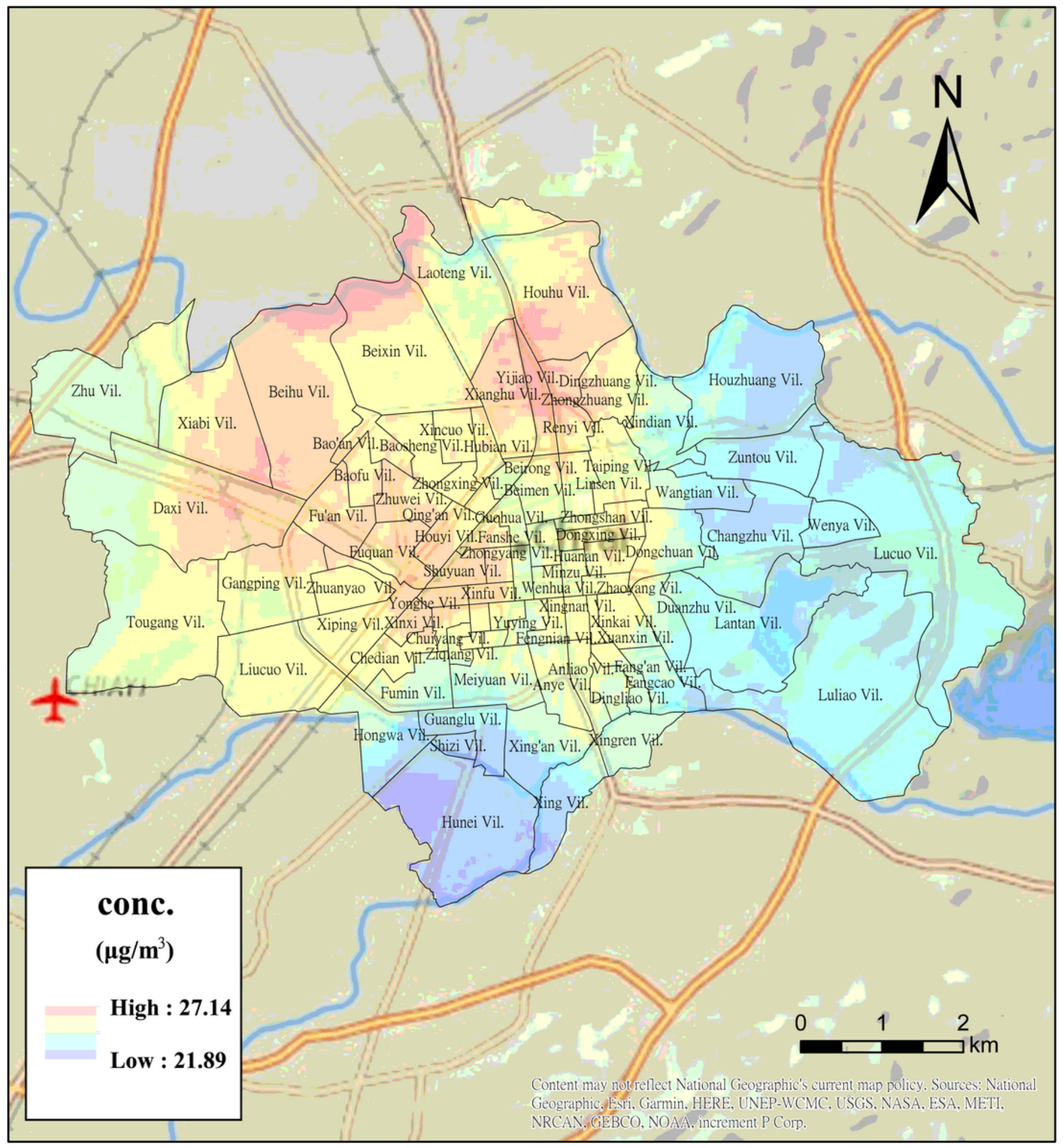

Figure 3

PM2.5 pollution concentration in Chiayi City (annual) 
Moran's Index: 0.978498

z-score: 53.801373

p-value: 0.000000

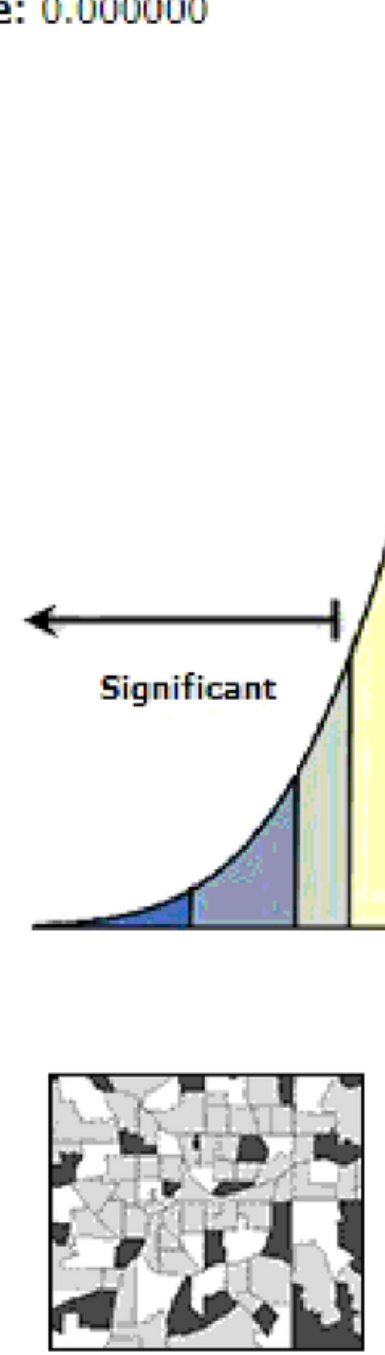

Dispersed

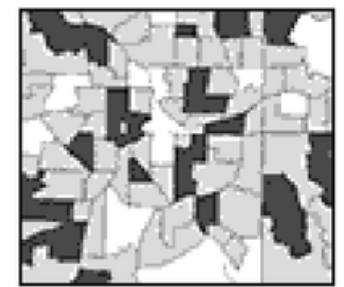

Random
Significance Level ( $p$-value)

0.01

0.05

0.10

...

0.10

0.05

0.01
Critical Value (z-score)

< -2.58

$-2.58--1.96$

$-1.96--1.65$

$-1.65-1.65$

$1.65-1.96$

$1.96-2.58$

$>2.58$

Given the z-score of 53.801372524 , there is a less than $1 \%$ likelihood that this clustered pattern could be the result of random chance.

Figure 4

Moran's I in Chiayi City 


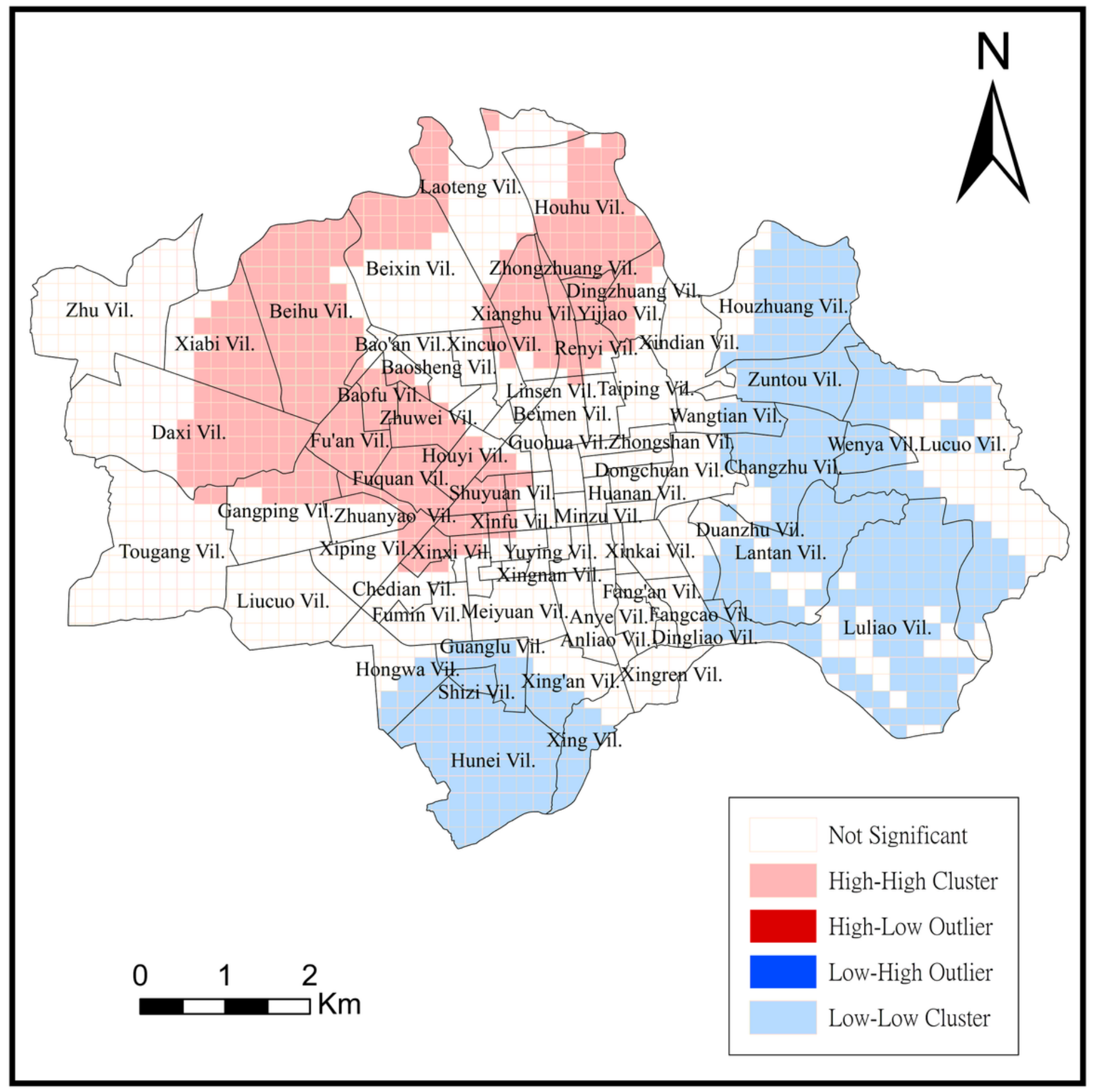

Figure 5

LISA in Chiayi City 
a

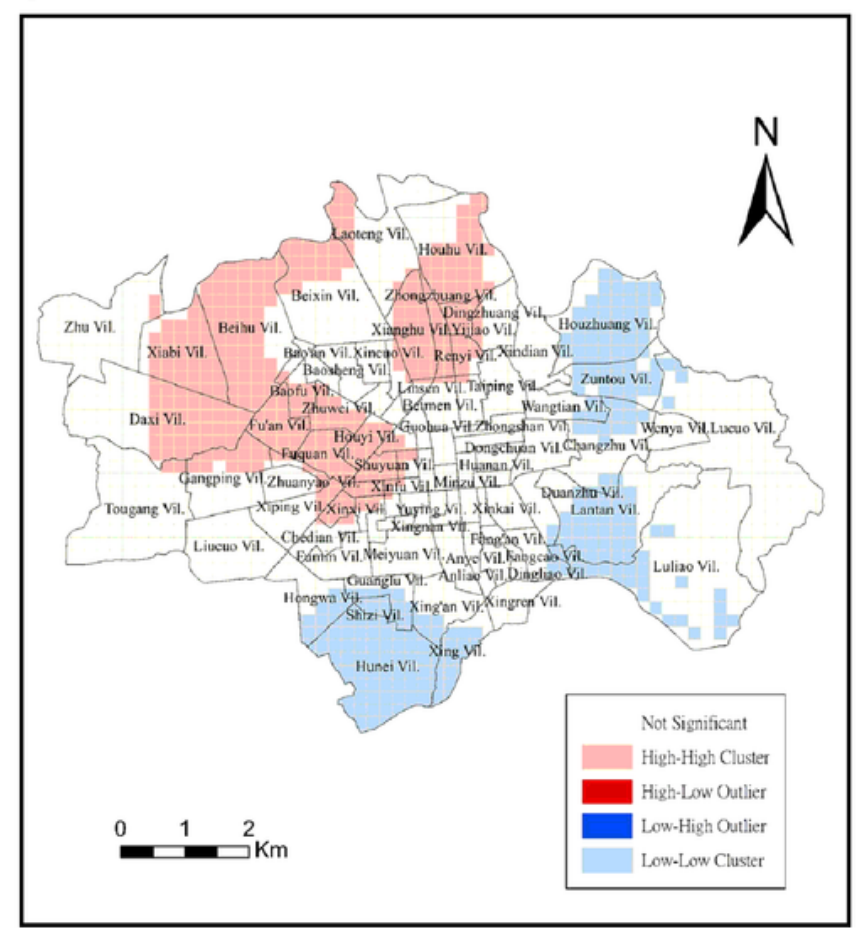

C

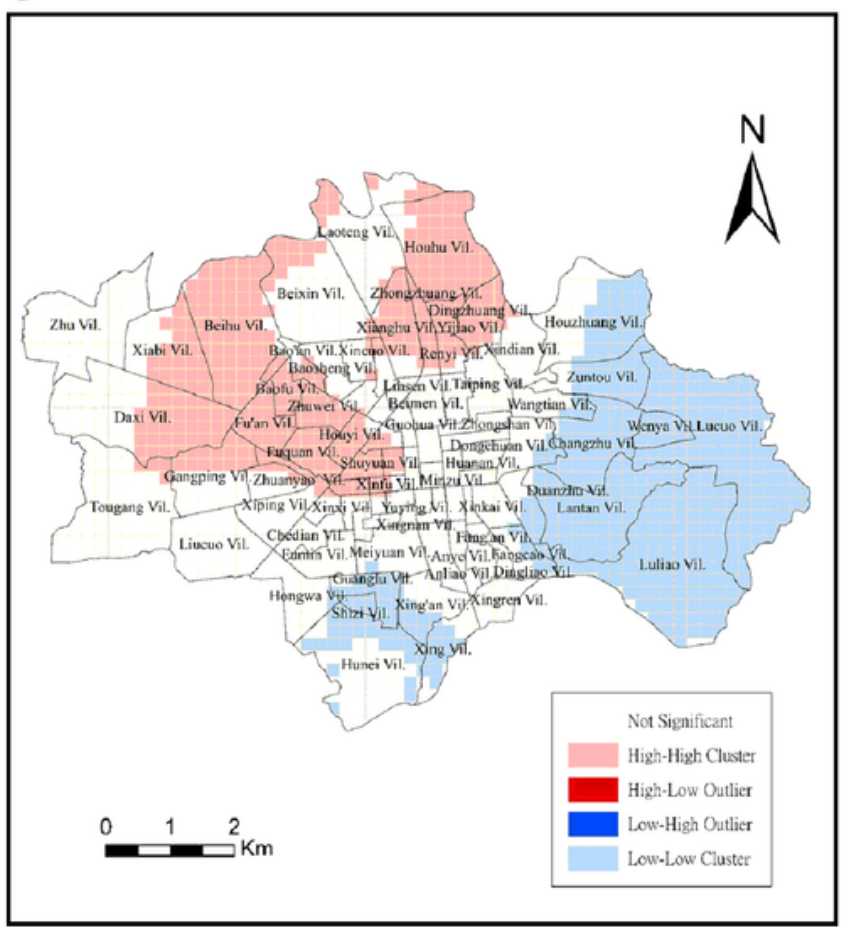

b

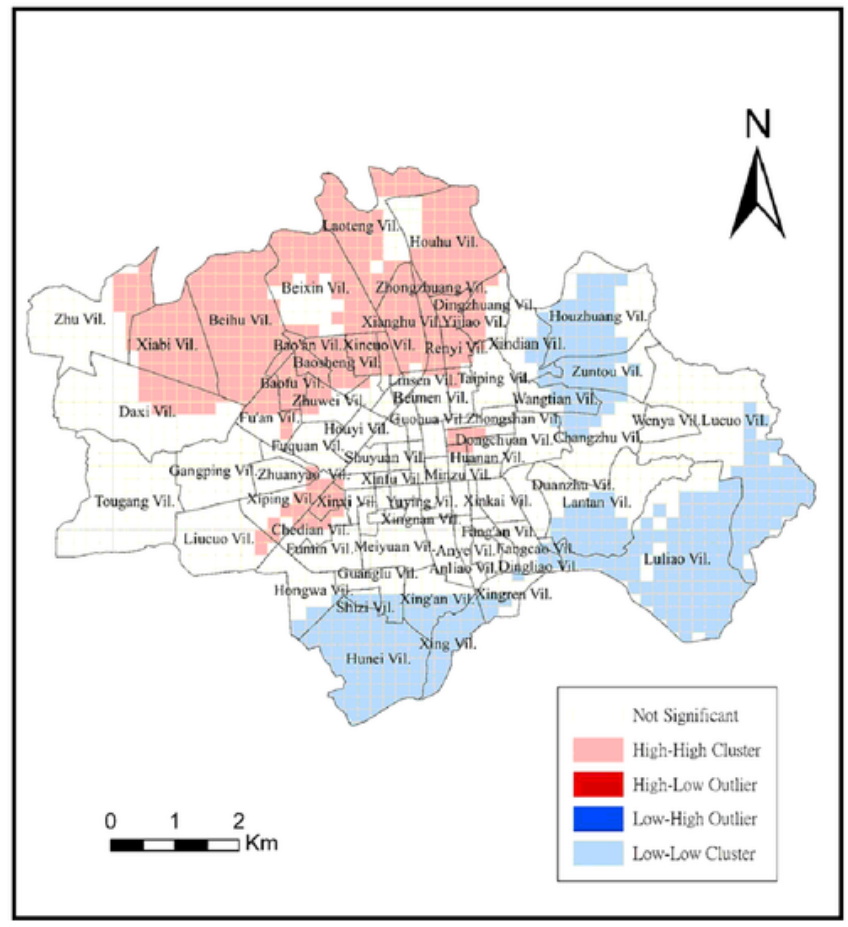

d

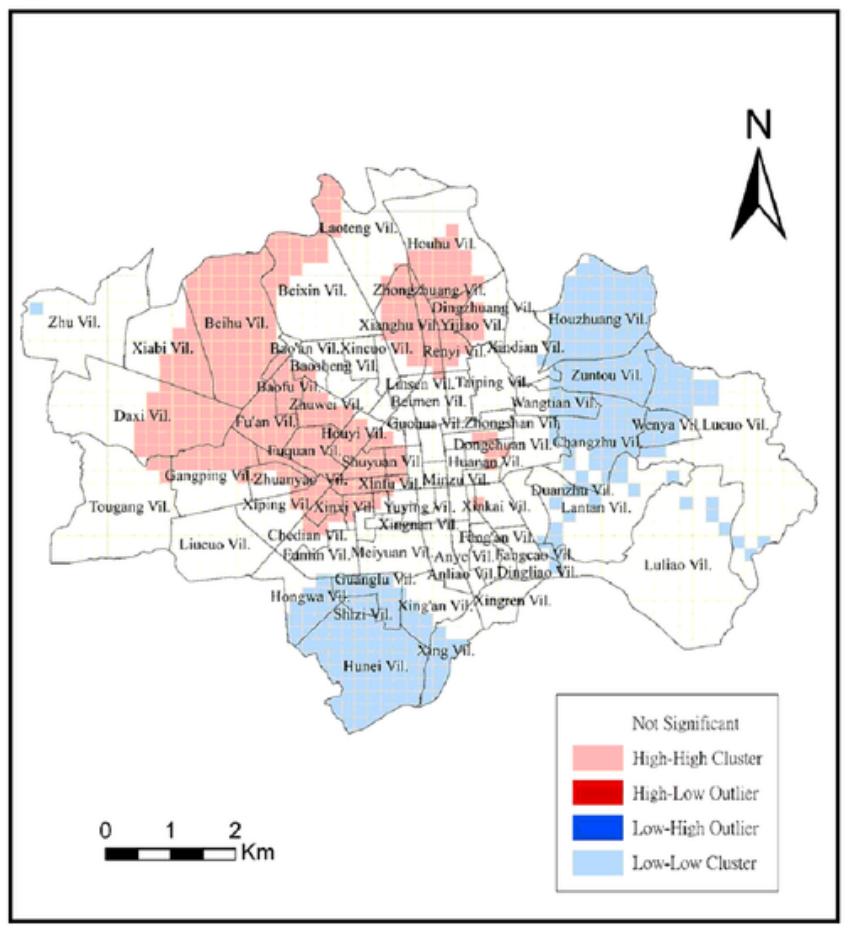

Figure 6

PM2.5 concentration LISA in Chiayi City (annual) 

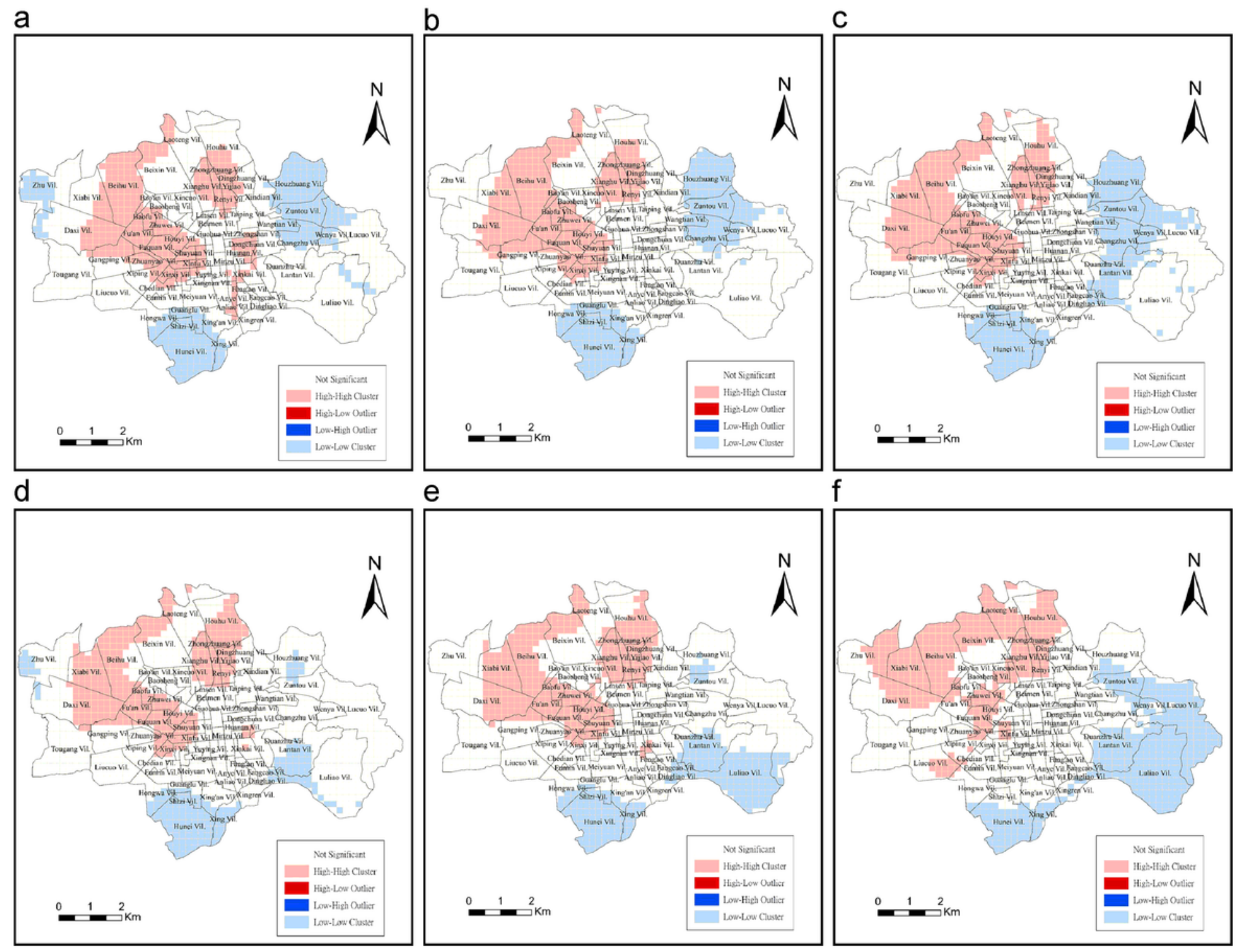

Figure 7

PM2.5 concentration LISA in Chiayi City (month) (1) 
a

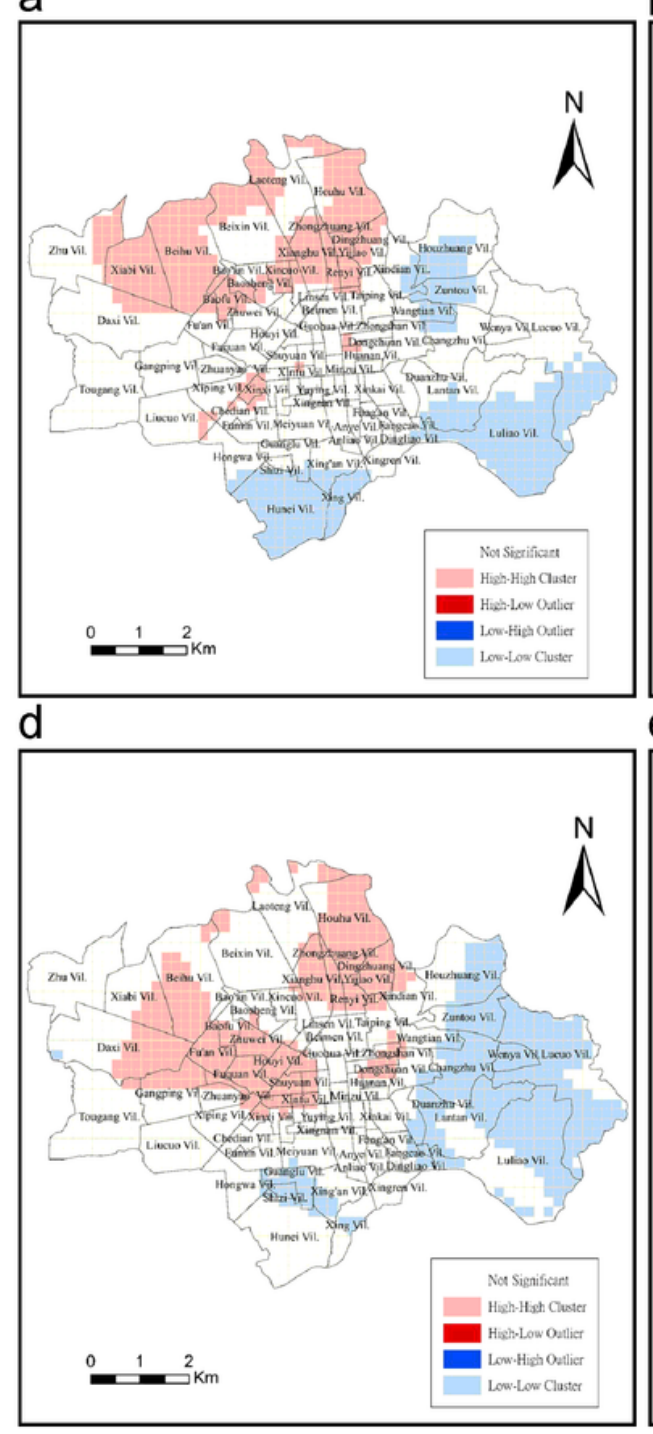

b
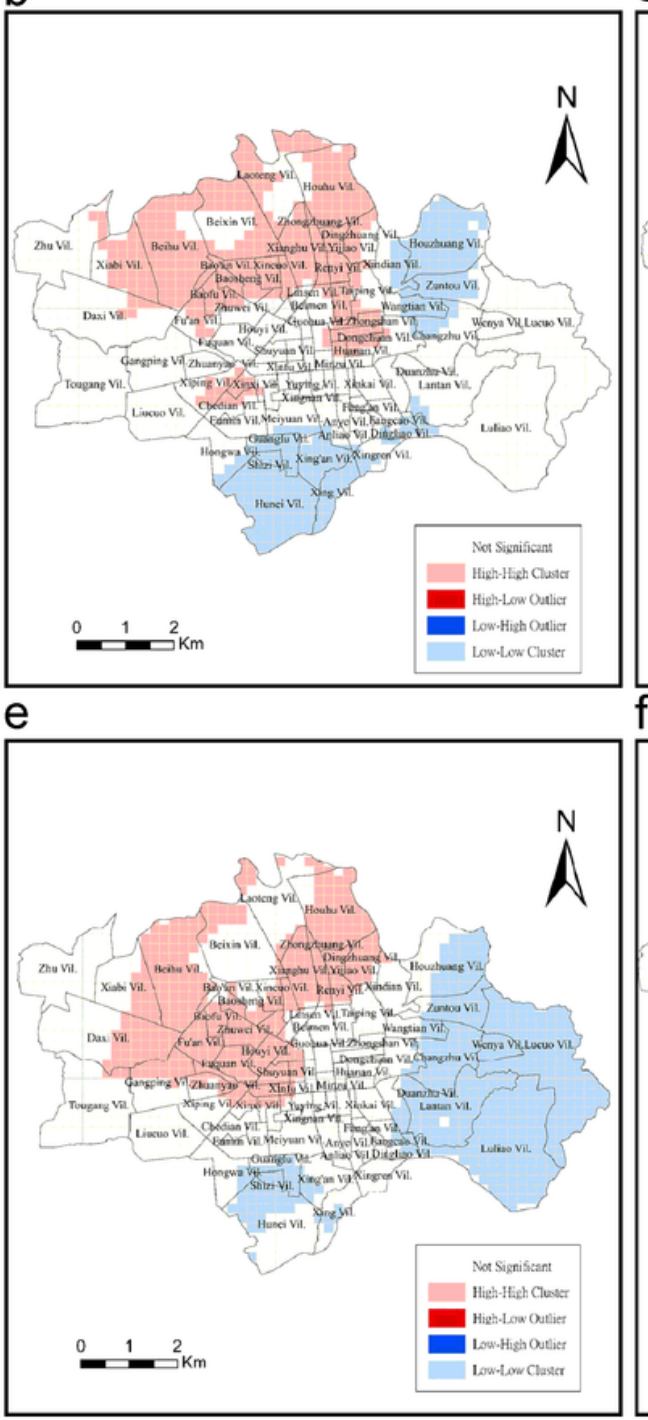

C
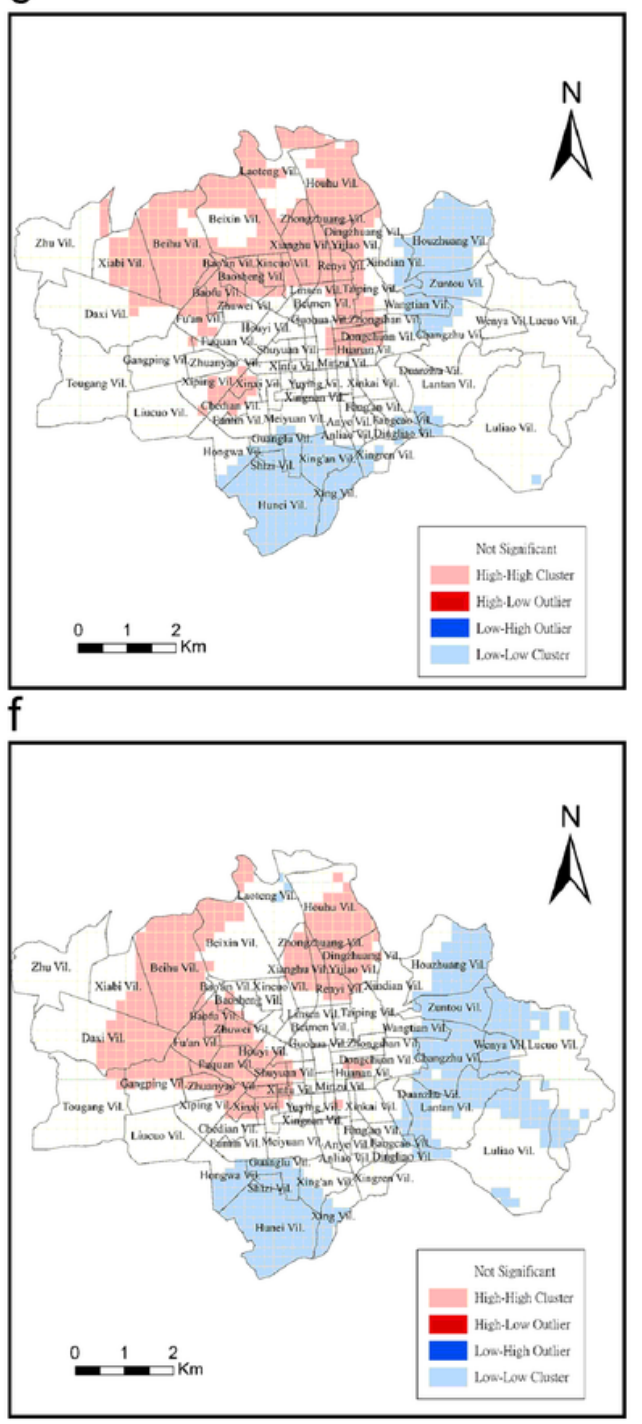

Figure 8

PM2.5 concentration LISA in Chiayi City (month) (2) 


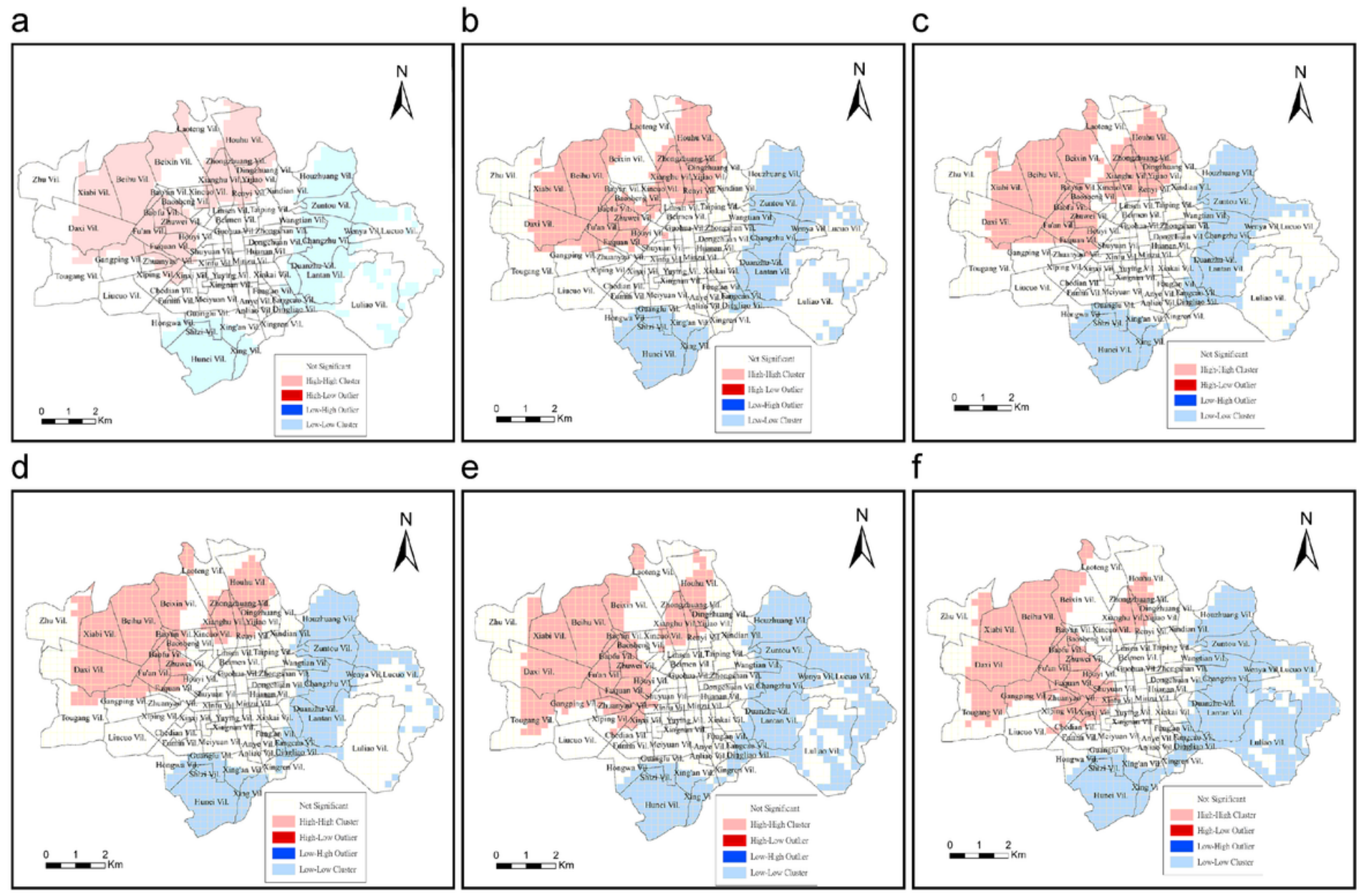

Figure 9

PM2.5 concentration LISA in Chiayi City (hour) (1) 
a
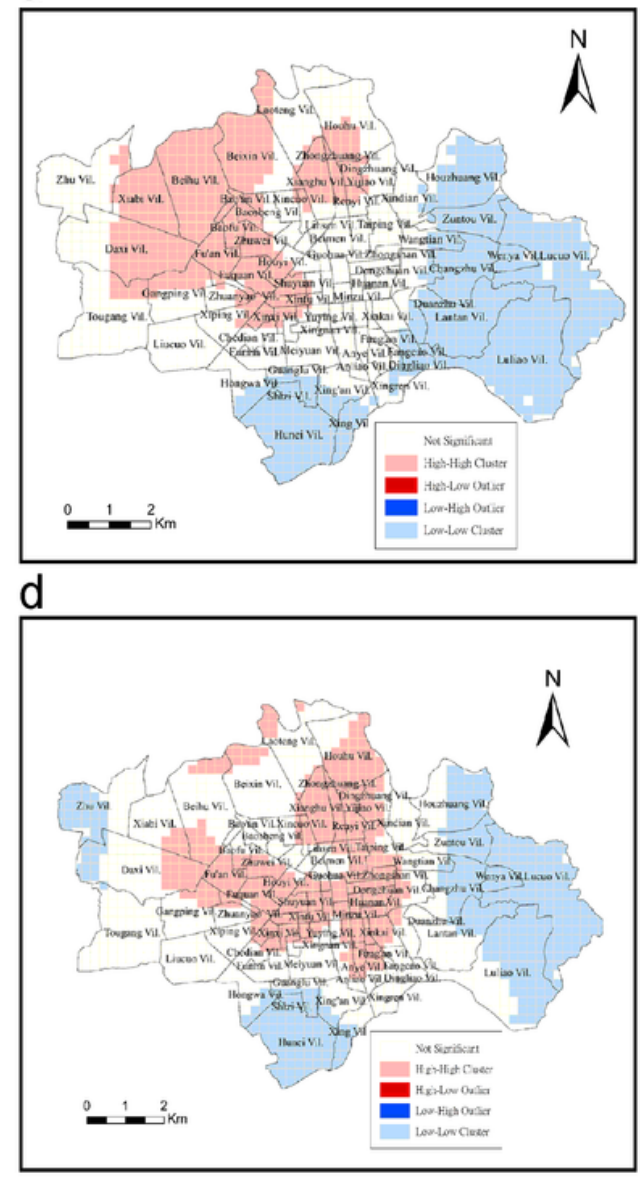

b
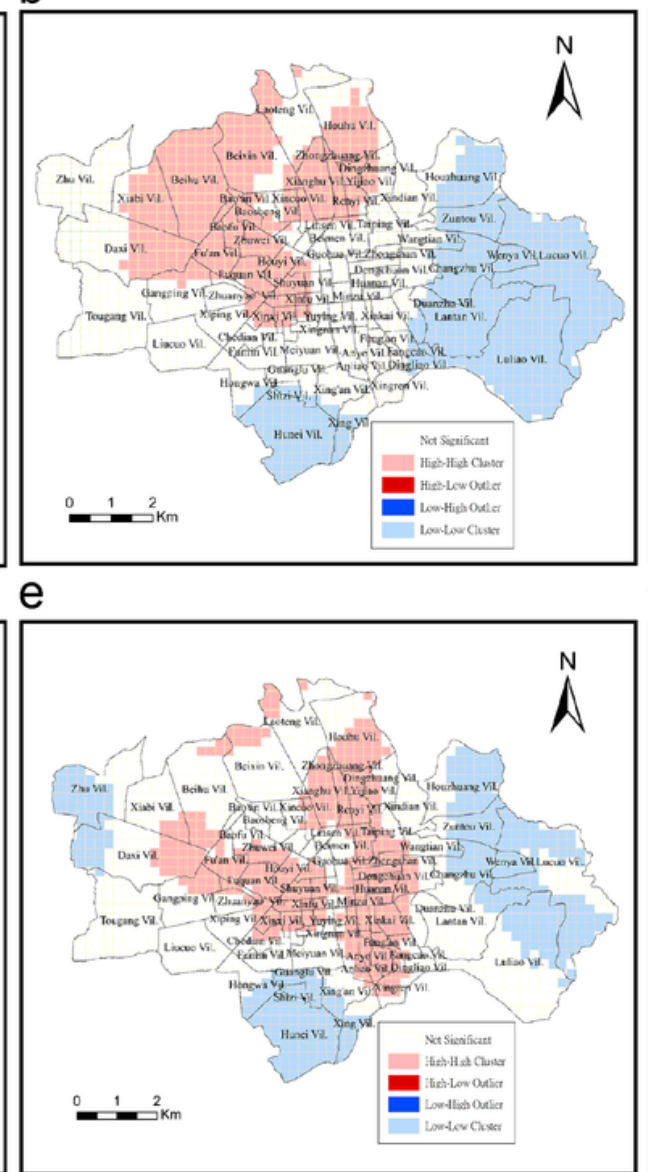

C
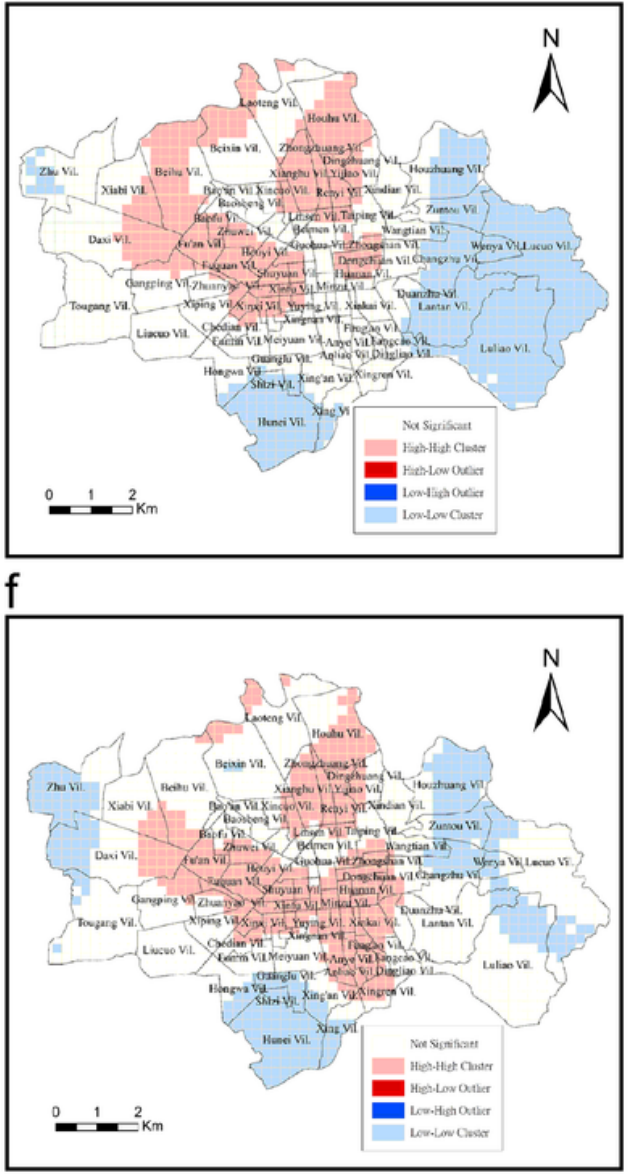

Figure 10

PM2.5 concentration LISA in Chiayi City (hour) (2) 
a

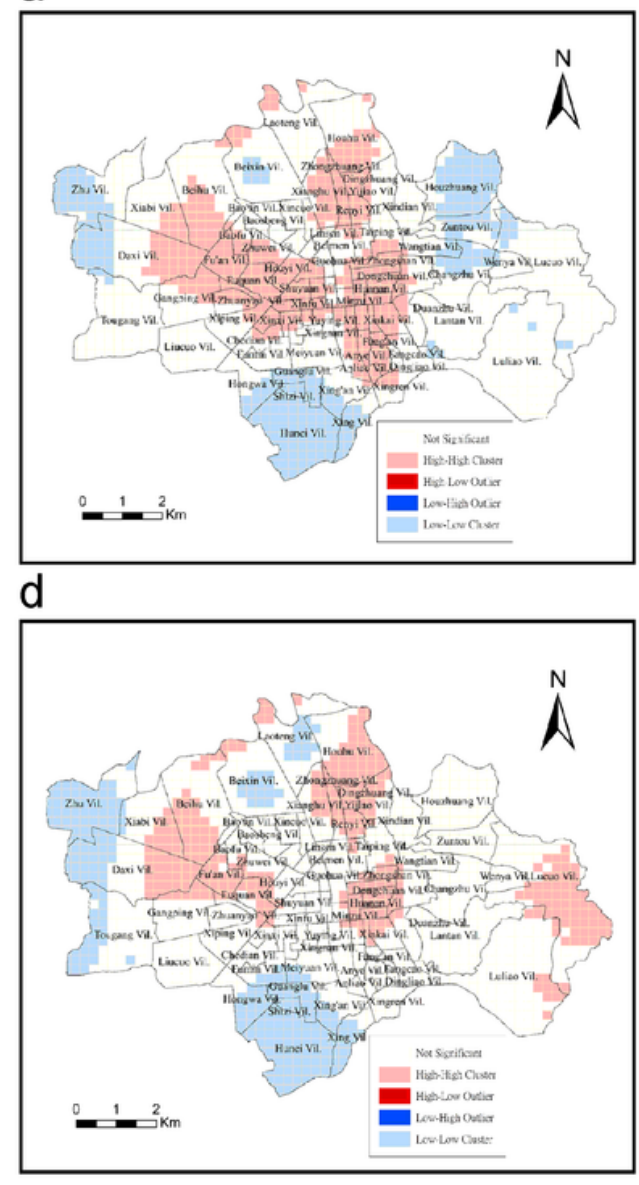

b

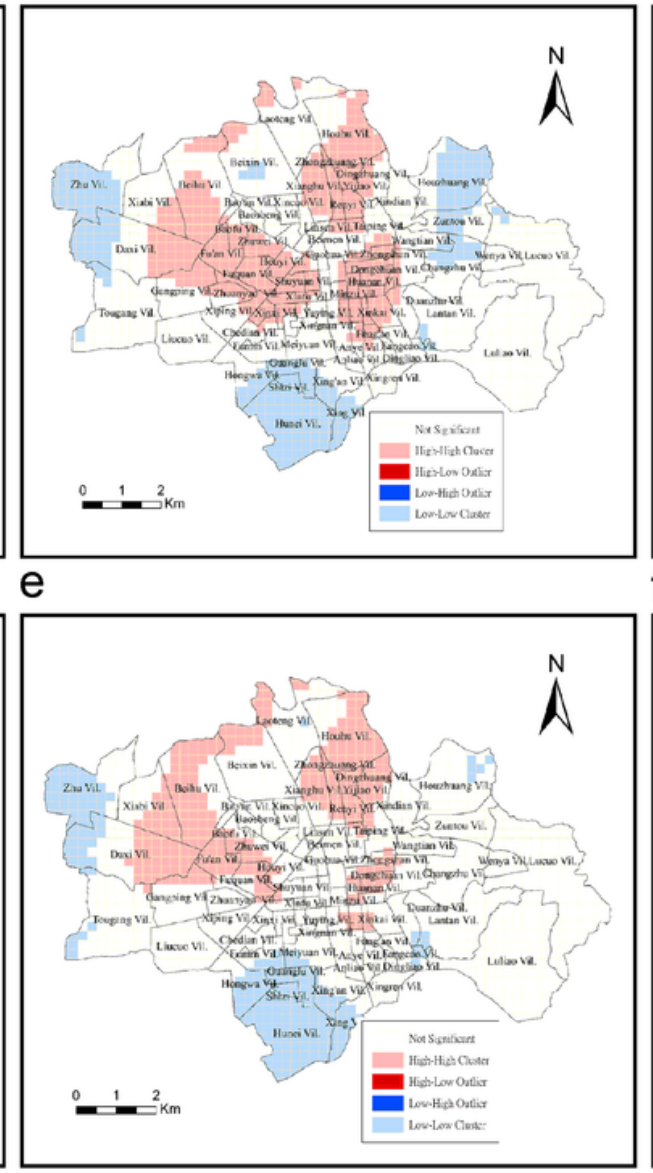

C
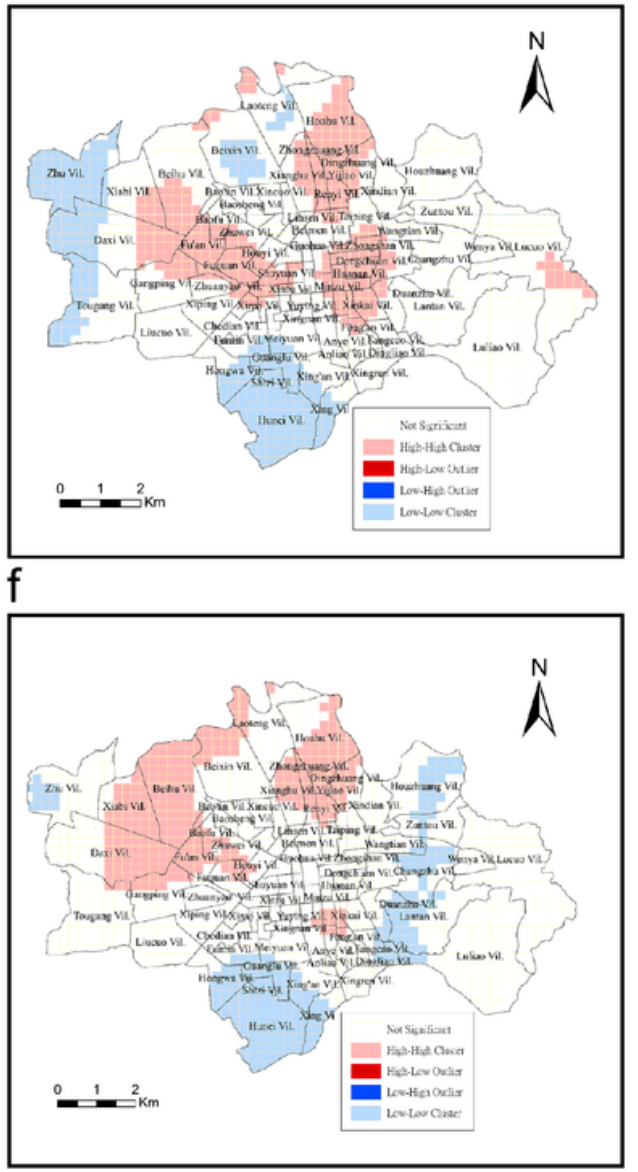

Figure 11

PM2.5 concentration LISA in Chiayi City (hour) (3) 
a

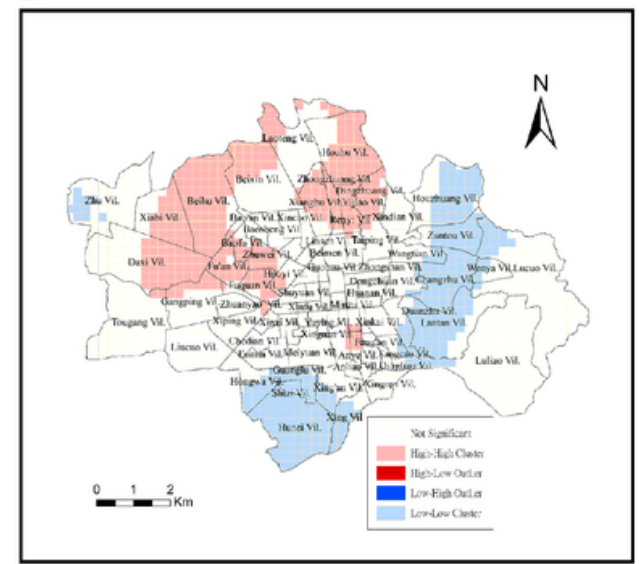

d

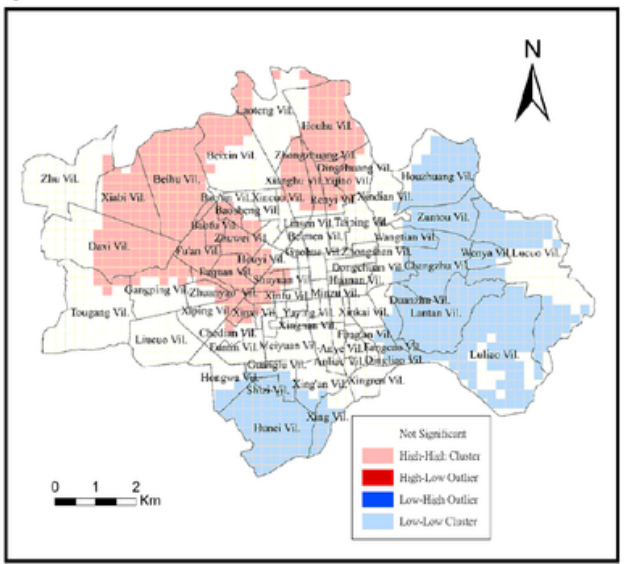

b

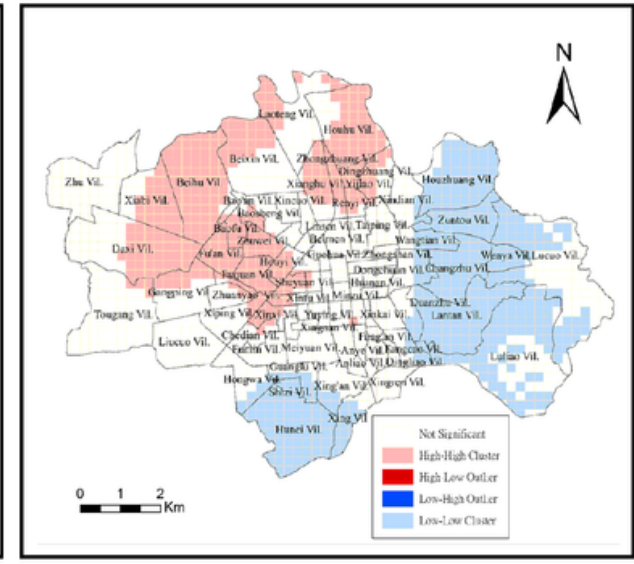

e

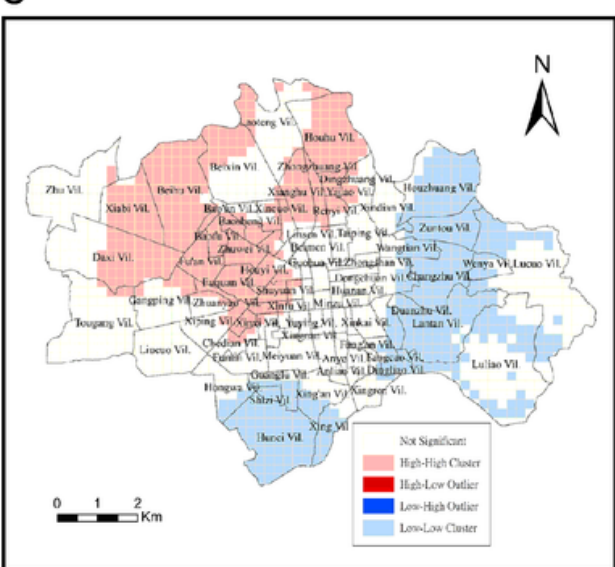

C
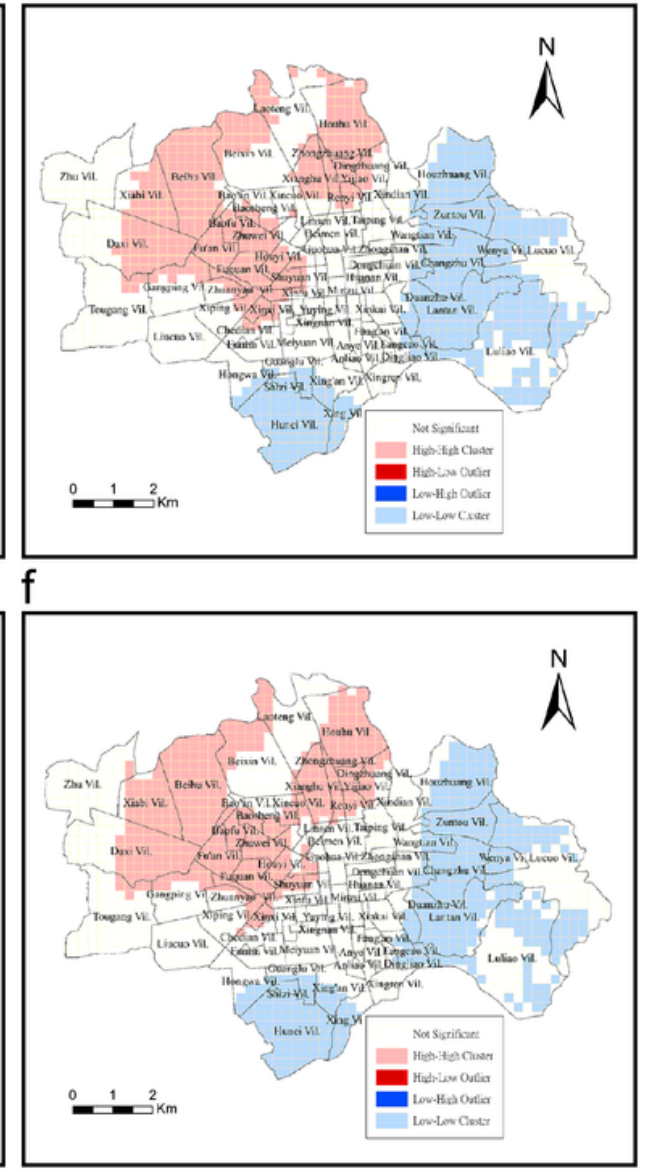

Figure 12

PM2.5 concentration LISA in Chiayi City (hour) (4) 